\title{
Changes in the Activity of Carbon and Nitrogen Metabolising Enzymes in Nodules of Bold and Small Seeded Lentil Cultivars
}

\author{
Vivek Chandra Verma ${ }^{1 *}$, Satvir Kaur ${ }^{1}$, Anil Kumar Gupta ${ }^{1}$, \\ Jagmeet Kaur $^{1}$, Sarvjeet Singh ${ }^{1}$ and Surabhi ${ }^{2}$ \\ ${ }^{1}$ Punjab Agricultural University, Ludhiana, Punjab-141004, India \\ ${ }^{2}$ GBPUA\&T, Pantnagar, Uttarakhand-263145, India \\ *Corresponding author
}

\section{A B S T R A C T}

\section{Keywords \\ Lentil, Nodules, \\ Seed size, Carbon and nitrogen metabolising enzyme.}

Article Info

Accepted:

26 October 2017

Available Online:

10 December 2017
Seed size is the important component for seed yield and an important trait for consumer preference. The seed size is governed by the genetic as well as environmental factors; however the enzymes responsible for the $\mathrm{C}$ and $\mathrm{N}$ compounds constitute the major seed biomass. To understand mechanisms governing seed size in lentil, the present investigation was carried out on carbon and nitrogen metabolism in nodules of two small (PL 4 and LL 699) and two bold (DPL 62 and IPL 406) seeded lentil cultivars during crop development. In spite of early flowering in bold seeded, they have sustained activities of carbon and nitrogen metabolising enzymes in them as compared to small seeded cultivars at later stages of development indicates that nodules in them remain active for a longer time. Nodules are site for metabolism of sucrose to provide the energy and carbon skeletons for biological nitrogen fixation. The activity of carbon metabolizing enzymes in nodules of bold seeded cultivars was found to be high. The activity of nitrogen metabolizing enzyme in nodules was found to be higher in all the cultivars during development. The main route for the assimilation of fixed nitrogen is GS/GOGAT pathway while GDH function at higher NH4+ concentration in young and senescing lentil nodules.

\section{Introduction}

Lentil (Lens culinaris L.) is one of the earliest cultivated crops and most nutritious rabi season food legumes as from plant-based food; lentil has the third highest level of protein $(26 \%)$ after soybeans and hemp and is an important constituent of the diet in many parts of the world, especially in Indian subcontinent which have large vegetarian populations (Tyagi and Khan, 2010). Lentil seeds contain $25 \%$ protein, $0.7 \%$ fat, $2.1 \%$ mineral, $0.7 \%$ fibre and $59 \%$ carbohydrate (Bhatty and Christison, 1984). It is rich in phosphorus, calcium, iron, zinc and carotene.
Due to presence of more protein, calcium and phosphorus it is preferred fodder for animals also as compared to wheat straw (Gupta et al., 2013). The seeds are consumed in North Africa, Middle East, West Asia and India as staple food as well as in vegetarian dishes worldwide providing essential nutrients such as proteins and micronutrients like iron and zinc. In developing countries, lentil straw is valued as animal feed (Erskine et al., 1990). It plays an important role in human, animal and soil health improvement occupying a unique position in cereal based cropping system 
(Hojjat 2011). Lentil ranks next only to chickpea in grain legume production (Dixit et al., 2011). The important lentil-growing countries of the world are India, Canada, Turkey, Bangladesh, Iran, China, Nepal and Syria. In India, lentil production in 2014-15 was 621.63MT and average yield was 471 $\mathrm{kg} / \mathrm{ha}$ representing total area of $1320 \mathrm{Ha}$ (IPGA 2015). Lentil is divided into two subspecies including macrosperma (broad and large seeds with a diameter of 9-6 $\mathrm{mm}$ ) and microsperma (concave shaped tiny seeds with a diameter of 6-2 mm) (Rathore, 2002). Singh et al., (2009) reported two groups in lentil namely microsperma $(<2.5 \mathrm{~g} / 100$ seed $)$ and macrosperma $(>2.5 \mathrm{~g} / 100$ seed). Seed vigour is influenced by seed size since it is generally proportional to the amount of food reserves that will be destined to the embryo (Lloret et al., 1999). Large seeds have an increased root/shoot ratio (Lloret et al., 1999) and higher grain yields (Rao 1981). Large seeds have a better performance than small seeds, especially under competitive conditions (Eriksson, 1999; Moles and Westoby, 2004). Superiority of larger seed size over smaller ones in terms of yield, plant vigour and weight in lentil has been reported (Sinha et al., 2009). Uniformity in seed size and constituents of seed lot has been emphasized for mechanical planting, better crop and determining the market price (Shahin et al., 2012). So identification of biochemical factors affecting or governing the seed size is very important. Seed size is not controlled at one level as it is the coordination of a number of biochemical and physiological factors at all developmental stages of the plant including nodulation, vegetative growth and reproductive establishment. Photosynthesis activity supplied large amount of energy to allow symbiotic nitrogen fixation in legume root. Sucrose is the stable product of photosynthesis that is transported from the tissue via the phloem into all heterotrophic tissues and is a source of energy and carbon metabolites (Stitt et al., 2010; Sun et al., 2011). Sucrose is synthesized in the leaves and exported through the phloem to sinks such as the nodules. Legume nodules are primarily dependent on the import and metabolism of sucrose to provide the energy and carbon skeletons for biological nitrogen fixation (Gordon et al., 1999). Photosynthates predominantly in the form of sucrose are translocated to nodules and are metabolized by cytosolic invertase and/or sucrose synthase (Aleman et al., 2010). Chopra et al., (1998) reported that alkaline invertase to be the major enzyme of sucrose metabolism. These reactions produce UDP-glucose and free hexoses, which, after phosphorylation by hexokinases enter the glycolytic or oxidative pentose phosphate pathways and are metabolized to Phosphoenol pyruvate (PEP). PEP is converted to oxaloacetic acid and then to L-malate by Phosphoenol pyruvate carboxylase (PEPC) (EC 4.1.1.31) and Malate dehydrogenase $(\mathrm{MDH}) \quad(\mathrm{EC} \quad 1.1 .1 .37$ ) respectively (Galvez et al., 2005). Malate provides a significant portion of carbon skeleton for the assimilation of fixed nitrogen and is the preferred substrate for bacteroid respiration (Lodwig and Poole, 2003). Two enzyme systems are considered of primary importance in ammonium assimilation. Coupled glutamine synthetase (GS)/NADHglutamate synthase (GOGAT) is the first pathway, where $\mathrm{NH}_{4}{ }^{+}$is incorporated into glutamine by GS, which is then converted with 2-oxoglutarate to glutamate by GOGAT. The second and alternative pathway is glutamate dehydrogenase (GDH) pathway which mediates the reductive amination of aketoglutarate to yield glutamic acid (Masclaux-Daubresse et al., 2006). Keeping these factors in mind it is important to ascertain the carbon and nitrogen metabolism in nodules affecting the seed size in lentil. Hence, it is important to study the enzymes of carbon and nitrogen metabolism in nodules of lentil cultivars differing in seed size. 


\section{Materials and Methods}

Two small (PL 4 and LL 699) and two bold seeded (DPL 62 and IPL 406) lentil cultivars were sown in the experimental area of Department of Plant Breeding and Genetics, Punjab Agricultural University,(30 $54^{\prime} \mathrm{N}$, $75^{\circ} 48^{\prime} \mathrm{E}$, elevation $247 \mathrm{~m}$ above sea level), Ludhiana, following recommended agronomic and crop management practices. The crop was sown in randomized block design with four replications of each cultivar.

\section{Extraction of nitrogen and carbon metabolizing enzymes}

The whole plants were uprooted in the morning from the wet field by random selection at 15 days interval between 50 and 110 days after sowing (DAS). The plants were brought to the laboratory buried in crushed ice, in an ice bucket. The roots bearing nodules were first thoroughly washed under tap water and then with distilled water so as to remove adhering soil particles on the nodules and then tapped dry in layers of filter paper. Fresh nodule samples were used for enzymatic analysis. All the enzymes were extracted (triplicates) with relevant precooled extraction buffers at $4^{\circ} \mathrm{C}$ to minimize denaturation and assayed at $30^{\circ} \mathrm{C}$. Sucrose synthase (SuSy, EC 2.4.1.13) was extracted by crushing the nodules (400-500 $\mathrm{mg}$ ) in a chilled mortar with a pestle with 3-4 ml of 20 $\mathrm{mM}$ HEPES buffer ( $\mathrm{pH} 8.2$ ) containing $1 \mathrm{mM}$ EDTA, $5 \mathrm{mM} \quad \mathrm{MgCl}_{2}$ and $5 \mathrm{mM} \quad \beta$ mercaptoethanol. Insoluble polyvinyl polypyrrolidone $(100 \mathrm{mg} / \mathrm{g}$ tissue $)$ was also added while extracting these enzymes. The extract was centrifuged at $10,000 \times$ g for 15 minutes at $4^{\circ} \mathrm{C}$. Alkaline invertases (AI, EC 3.2.1.27) were extracted in a similar manner as sucrose synthase except that $0.02 \mathrm{M}$ sodium phosphate buffer ( $\mathrm{pH}$ 7.5) is used instead of HEPES buffer ( $\mathrm{pH}$ 8.2). Glutamine synthetase (GS, EC 6.3.1.2 L-glutamate:ammonia ligase), glutamate synthase or Glutamine 2oxoglutarate aminotransferase (GOGAT, EC 1.4.1.14), glutamate dehydrogenase (GDH, EC 1.4.1.2), Phosphoenolpyruvate carboxylase (PEPC, EC 4.1.1.31), Malate dehydrogenase (MDH, EC 1.1.1.37) and Isocitrate dehydrogenase (IDH, EC 1.1.1.42) were extracted by homogenizing the nodules in $0.1 \mathrm{M}$ Tris- $\mathrm{HCl}$ buffer $(\mathrm{pH}$ 7.5). The homogenate was centrifuged at $10,000 \mathrm{xg}$ for 20 minutes and the clear supernatant was used for the enzyme assay.

\section{Estimation of nitrogen and carbon metabolizing enzymes}

Glutamine synthetase was assayed by the method of Elliot (1953) with some modifications. The assay mixture contained $0.2 \mathrm{M}$ Tris- $\mathrm{HCl}$ buffer (pH 7.5), $0.5 \mathrm{M}$ $\mathrm{MgSO}_{4} .7 \mathrm{H}_{2} \mathrm{O}, 0.5 \mathrm{M} \mathrm{NH}_{2} \mathrm{OH} . \mathrm{HCl}$ and $0.5 \mathrm{M}$, $0.06 \mathrm{M}$ ATP, enzyme extract and $0.6 \mathrm{M}$ sodium glutamate. Incubate the reaction mixture at $30^{\circ} \mathrm{C}$ for $2 \mathrm{~h}$ and add $\mathrm{FeCl}_{3}$ reagent. The clear supernatant obtained after centrifugation at $6,000 \times \mathrm{g}$ for $10 \mathrm{~min}$ was measured at $540 \mathrm{~nm}$. Glutamine 2oxoglutarate aminotransferase was asssayed by the method of Misra and Oaks (1981) with some modification. GOGAT was assayed at $340 \mathrm{~nm}$. The reaction mixture contained 0.1 $\mathrm{M}$ Tris- $\mathrm{HCl}$ buffer (pH 7.6), 0.2 M Lglutamine, $0.2 \mathrm{M}$ 2-oxoglutarate, $0.5 \mathrm{M} \mathrm{KCl}$, $0.04 \mathrm{M}$ EDTA, 2\%, $\beta$-mercaptoethanol (v/v), $0.002 \mathrm{M}$ NADH and $0.2 \mathrm{ml}$ enzyme extract. Glutamate dehydrogenase was assayed by the method of Duke and Ham (1976). GDH was assayed at $340 \mathrm{~nm}$. The reaction mixture contained $0.1 \mathrm{M}$ Tris- $\mathrm{HCl}$ buffer $(\mathrm{pH} 7.6)$, $3 \mathrm{M} \mathrm{NH} \mathrm{NH}_{4} \mathrm{Cl}, 0.33 \mathrm{M}$ 2-oxoglutarate, $1 \mathrm{mM}$ $\mathrm{NADH}$ and $0.2 \mathrm{ml}$ enzyme extract. PEPC, $\mathrm{MDH}$ and IDH were from the rate of oxidation of NADH assayed spectrophotometrically at $340 \mathrm{~nm}$ by the methods of Christeller et al., (1977), Vance and Stade (1984) and Kerr et al., (1987) 
respectively with some modification. Alkaline invertase and sucrose synthase were assayed by the method of Dey (1986) and Nelson (1944) respectively with some modification. The protein content of enzyme extract was measured by the method of Lowry et al., (1951) using bovine serum albumin as a standard.

\section{Statistical analysis}

The results were statistically analyzed by using factorial closed randomized design (CRD) to identify the significant relation between the cultivars and biochemical parameters at different days after sowing (DAS).

\section{Results and Discussion}

The specific activity of sucrose synthase (SuSy) in PL 4 and LL 699 increases upto 80 DAS whereas in bold seeded cultivars it increased upto 95 DAS (Fig. 1a). It was observed that specific activity of alkaline invertase (AI) in nodules increased upto 80 DAS in all cultivars thereafter it decreased. At 80 DAS alkaline invertase activity was found to be maximum in small seeded cultivars (PL 4) and minimum in bold seeded cultivars (DPL 62). At 95 DAS the activity of AI was found to be more in nodules of LL699 (small seeded cultivars) and IPL 406 (bold seeded cultivars) as compared to other cultivars, but at 110 DAS the activity decreased in all cultivars (Fig. 1b). It was observed that PEPC in PL 4 and LL 699 increased upto 95 DAS and thereafter it decreased whereas in DPL 62 maximum activity was observed at 80 DAS and in IPL 406 it increased upto 110 DAS (Fig. 1c).

Malate dehydrogenase (MDH) was found to be more in IPL 406 at 65 DAS as compared to all cultivars thereafter it decreased (Fig. 2a). At 110 DAS the specific activity of MDH was found to be maximum in DPL 62 (bold seeded cultivars) followed by LL 699 (small seeded cultivars) and then PL4. The specific activity of isocitrate dehydrogenase (IDH) increases upto110 DAS and no significant differences were found in the cultivars (Fig. 2b).

The activity of glutamine synthetase (GS) and glutamate synthase (GOGAT) was found to be comparable in all the cultivars, however glutamate dehydrogenase activity was found to be maximum between 65-80 DAS in all the cultivars. GDH activity was found to be highest in bold seeded cultivars (DPL 62 and IPL 406) followed by small seeded cultivars (PL 4 and LL 699) at 80 DAS (Figs. 3a, b and c). Lentil is an important pulse crop containing high levels of protein (22-35\%), including the essential amino acids such as isoleucine and lysine. Seed size and shape are important factors influencing trade in pulse grains and determine market price as well as yield (Shahin et al., 2012). Seed size in lentil is the result of interlinked stages starting from nodule establishment; finally the source-sink relationship affecting seed size and the difference in these attributes will contribute towards difference in seed size in them.

The higher activity of sucrose synthase in both the bold seeded cultivars; higher PEPC in DPL 62 at 80 DAS and in IPL406 at 110 DAS; higher MDH in IPL406 at 65 DAS and higher MDH and IDH in DPL 62 at 110 DAS; higher GDH in DPL 62 and IPL406 at 65 DAS and even comparable enzyme activities in bold seeded cultivars with small seeded cultivars were observed although the bold seeded cultivars flower 10-15 days earlier than small seeded cultivars, but the activity of carbon nitrogen assimilating enzymes in nodules of these cultivars even after flowering was comparable to small seeded cultivars. Thus the nodules in bold seeded cultivars remain active for longer time. 
Fig.1 Specific activity of (a) sucrose synthase (b) alkaline invertase (c) phosphoenolpyruvate carboxylase in nodules of small (PL 4 and LL 699) and bold (DPL 62 and IPL 406) seeded lentil cultivars at different days after sowing (DAS)

(a)

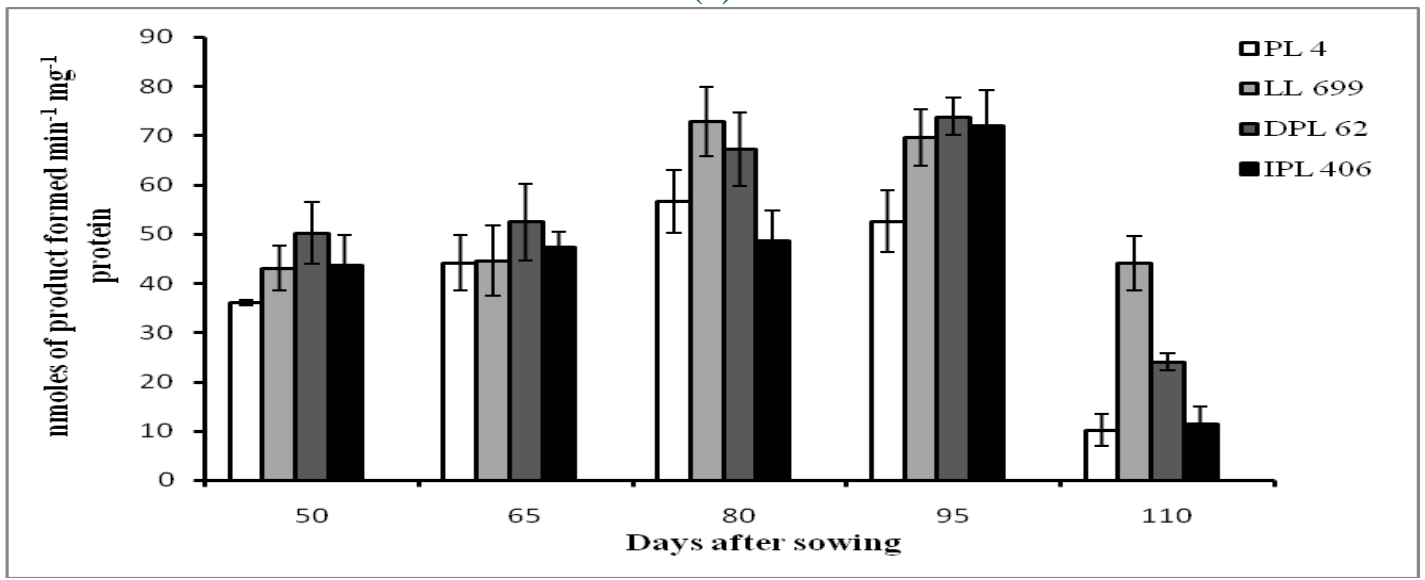

(b)

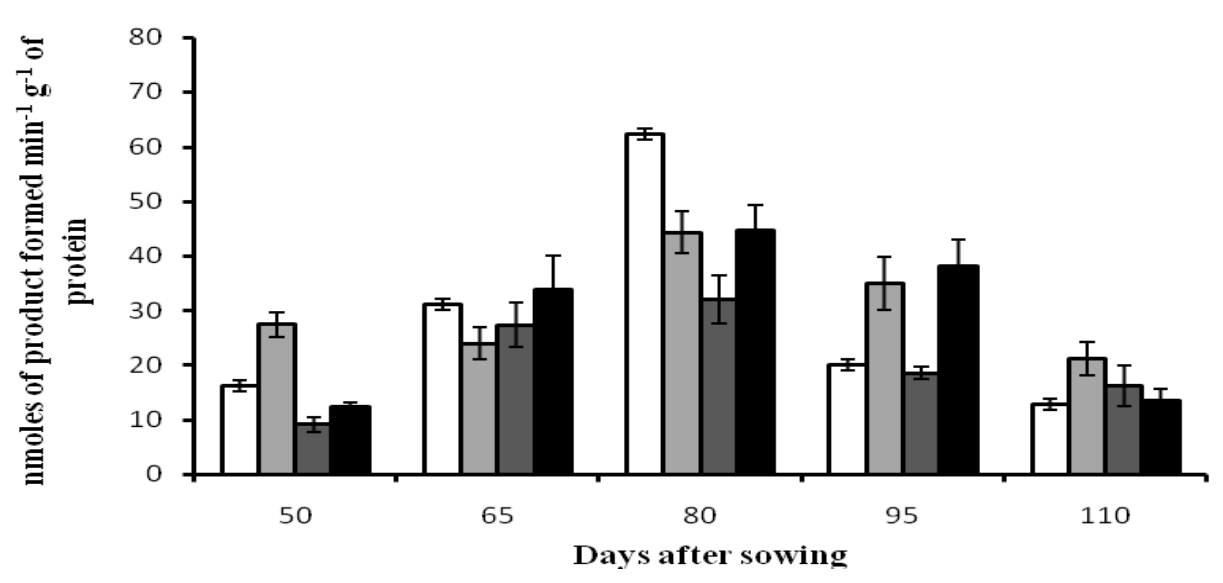

(c)

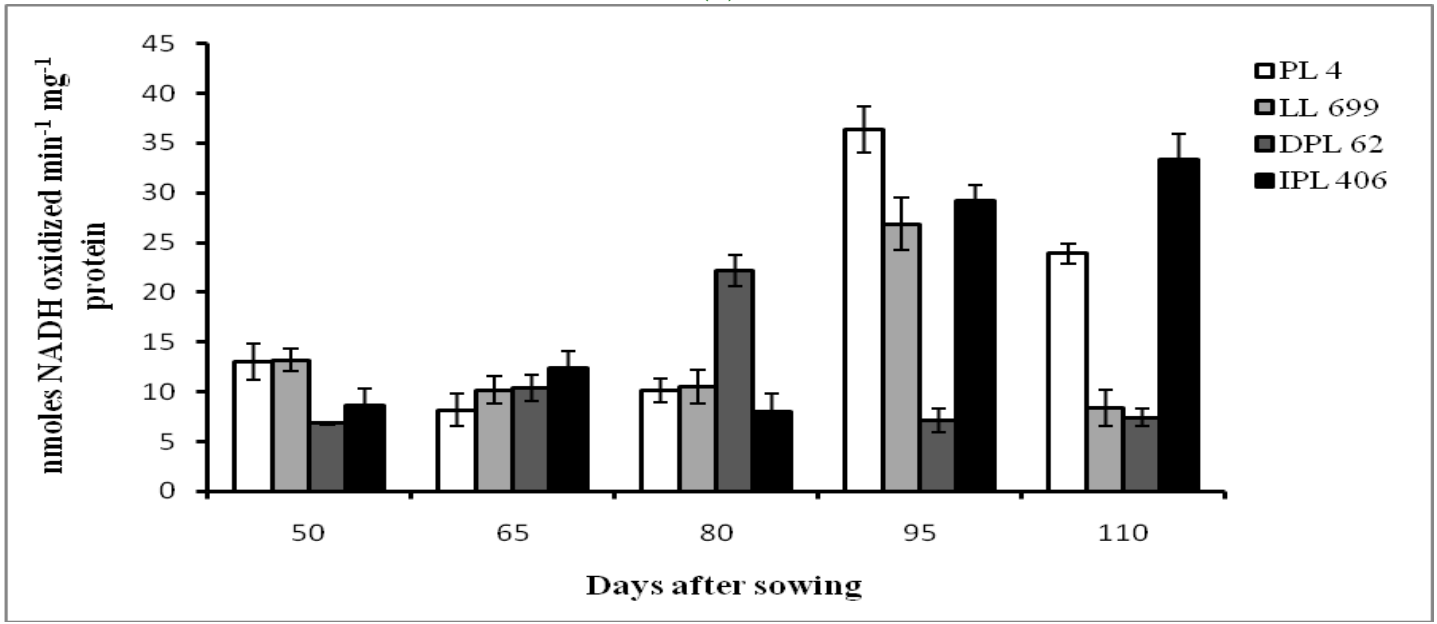


Fig.2 Specific activity of (a) malate dehydrogenase (b) isocitrate dehydrogenase in nodules of small (PL 4 and LL 699) and bold (DPL 62 and IPL 406) seeded lentil cultivars at different days after sowing (DAS)

(a)

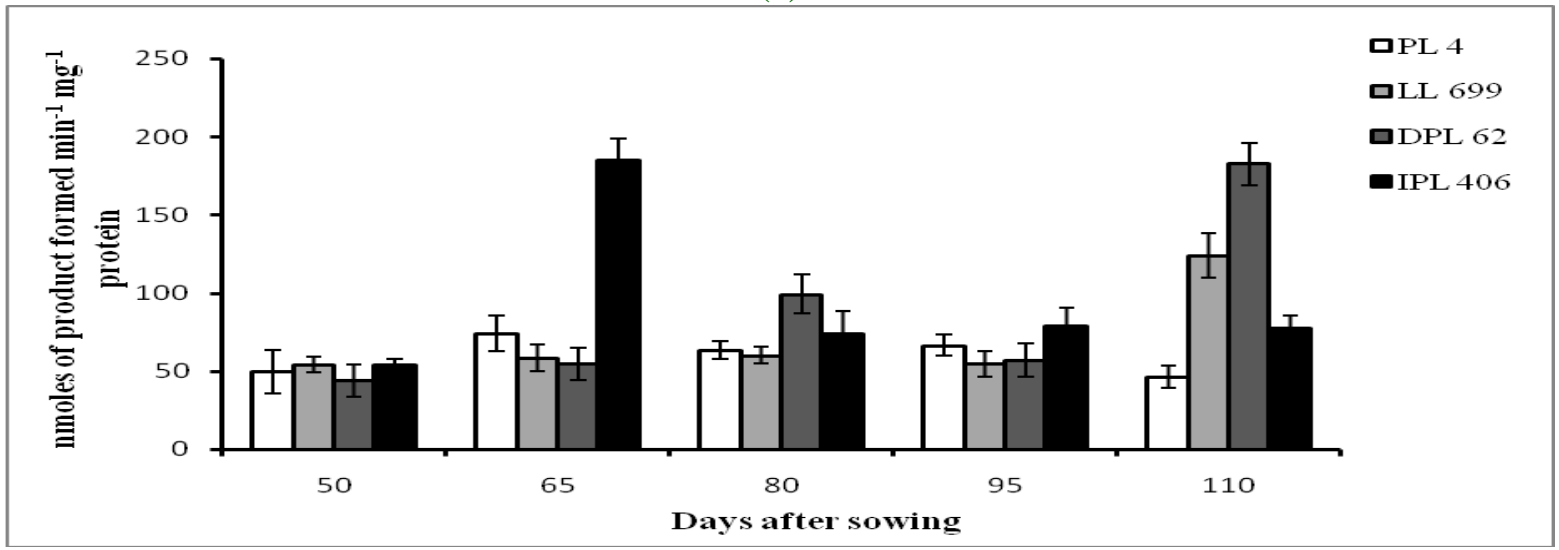

(b)

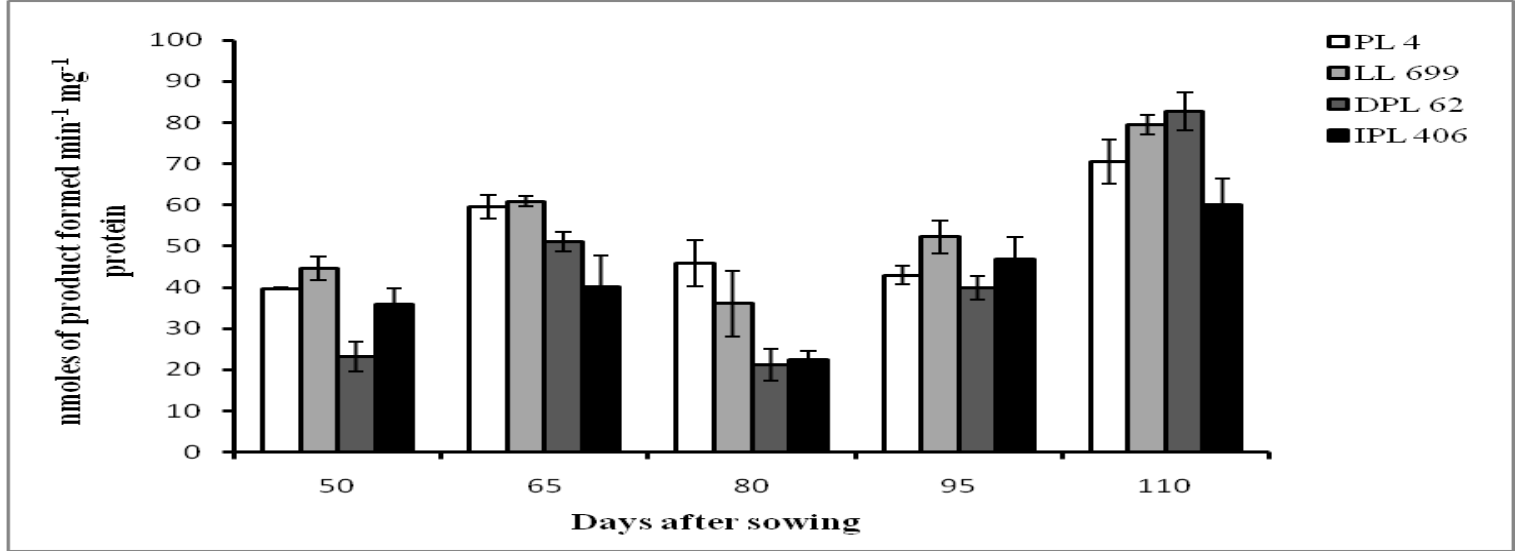

Fig.3 Specific activity of (a) glutamine synthatase (b) glutamate synthase (c) glutamate dehydrogenase in nodules of small (PL 4 and LL 699) and bold (DPL 62 and IPL 406) seeded lentil cultivars at different days after sowing (DAS)

(a)

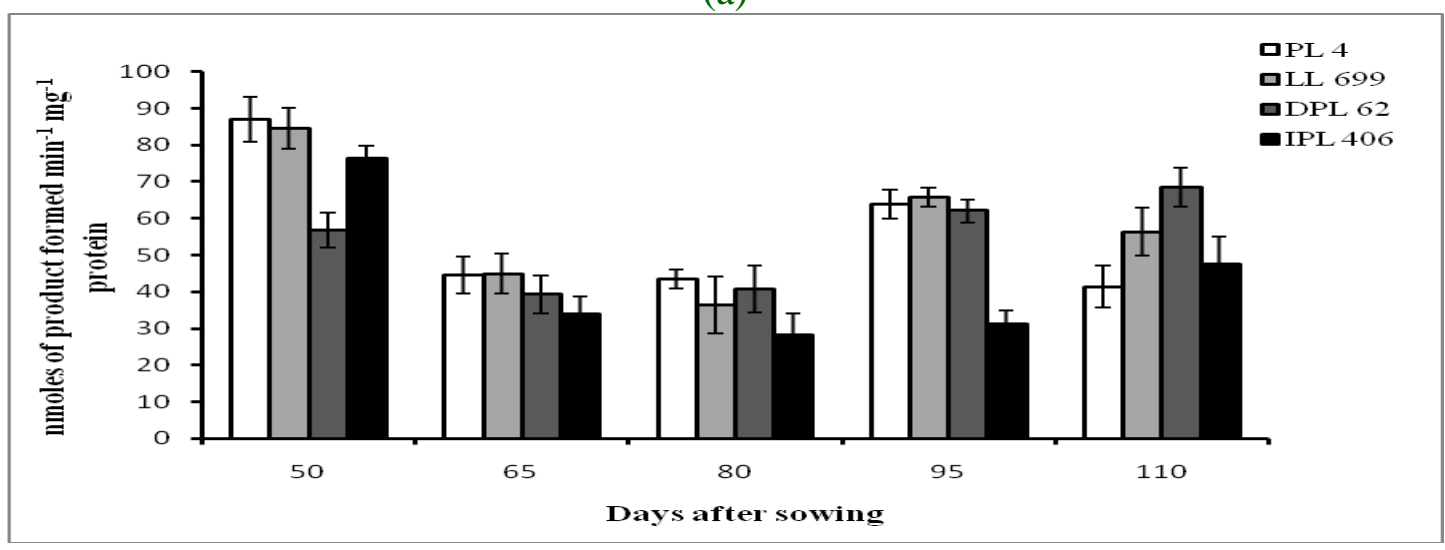


(b)

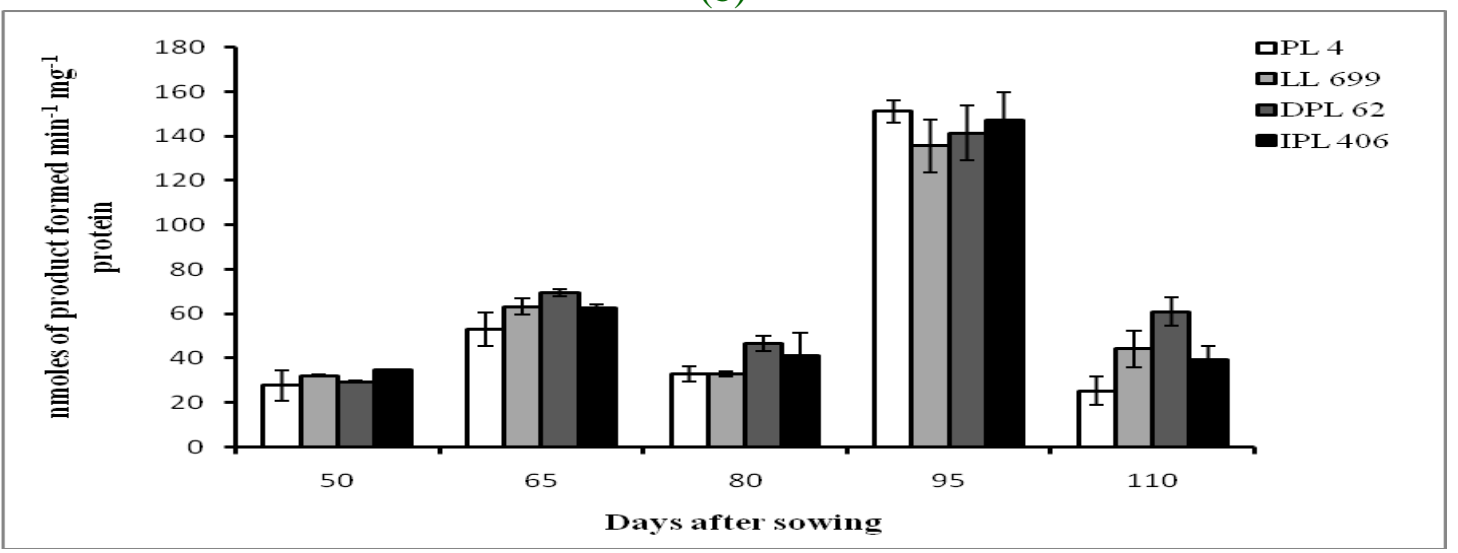

(c)

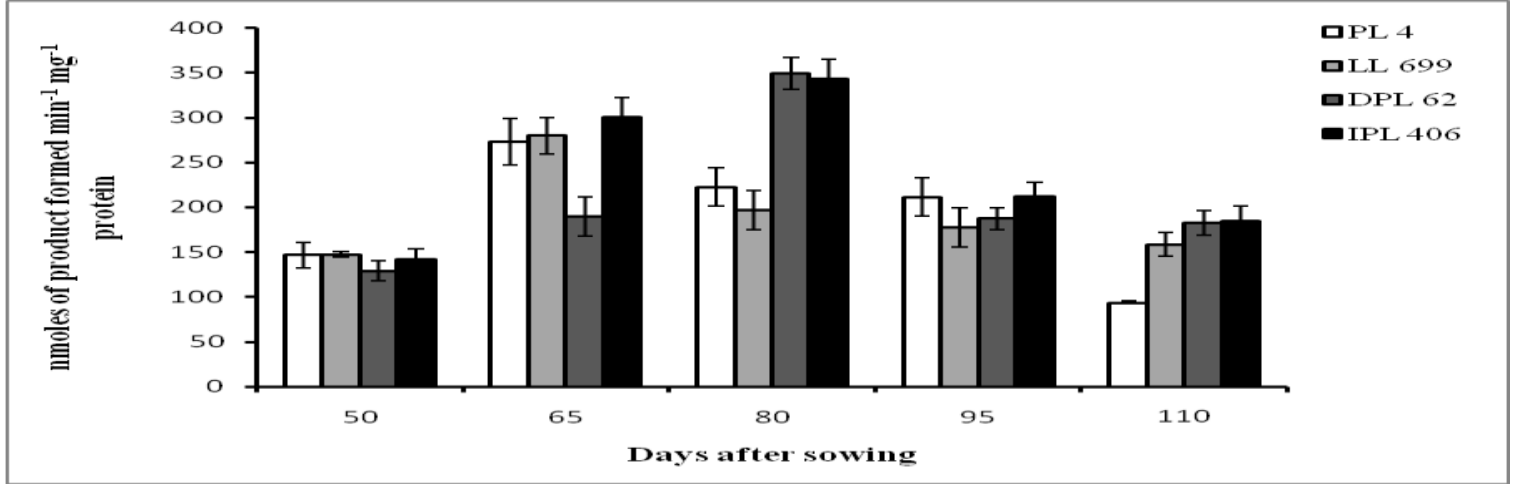

Sucrose is the main carbohydrate transported through phloem to sink tissues like nodules, where it is metabolized by either sucrose synthase $(\mathrm{SuSy})$ or alkaline invertase (AI) and the breakdown of sucrose into glucose and fructose, are essential proteins in plant life (Aleman et al., 2010; Mariana et al., 2013).The higher sucrose synthase activity observed in the nodules of bold seeded cultivars ensures hexose supply for meeting the energy and reducing power demands of nodules during the stage of active nitrogen fixation and probably may regulate carbon metabolism and nitrogen fixation (Chopra et al., 2003). In present investigation bold seeded cultivars showed higher status of PEP, $\mathrm{MDH}$ and IDH enzymes that indicate the utilization of glycolytic products for bacteroid respiration. The products of SuSy after phosphorylation by hexokinases enter the glycolytic pathway and are metabolized to phosphoenolpyruvate (Galvez et al., 2005). PEP is converted to oxaloacetic acid and then to L-malate by phosphoenolpyruvate carboxylase and malate dehydrogenase, respectively (Gordon et al., 1999). PEPC mediates the flow of carbon for the production of dicarboxylic acid which are the main products of sucrose degradation supplied to bacteroid to support nitrogen fixation in nodules (Lodwig and Poole, 2003). A down regulation of PEPC in nodules impairs the nitrogen fixation whereas up regulation of malate dehydrogenase has been reported to increase nitrogen fixation (Normura et al., 2006; Schulze et al., 1998). Isocitrate dehydrogenase (IDH) is NADPHproducing enzyme catalyzes the conversion of isocitrate to 2-oxoglutarate (2OG) and providing carbon skeleton for ammonium assimilation and therefore amino acid metabolism (Hodges, 2002). Two enzyme 
systems are considered of primary importance in ammonium assimilation. First is glutamate dehydrogenase (GDH) and second is glutamine synthetase (GS)/glutamate synthase (GOGAT). Glutamine synthetase (GS) is the key enzyme in charge of glutamine biosynthesis in nature. The reaction catalyzed by glutamine synthetase involves the ATP dependent amination of glutamate to yield glutamine. Glutamate synthase (GOGAT) then catalyzes the transfer of the amide group from glutamine to $\alpha$-ketoglutarate to yield two molecules of glutamate. This is referred as GS/GOGAT pathway (Miflin and Lea, 1980). The predominant GS/GOGAT enzymes are chloroplastic GS2 and Fd-GOGAT and cytosolic GS1 and NADH-GOGAT (Tobin and Yamaya, 2001). Chopra et al., (2002) reported that GS and GOGAT function as the main route for the assimilation of fixed nitrogen while GDH may function at higher $\mathrm{NH}_{4}{ }^{+}$concentration in young and senescing lentil nodules.

It was concluded that the activity of both $\mathrm{C}$ and $\mathrm{N}$ metabolizing enzyme were higher in bold seeded lentil cultivar. The higher sucrose synthase activity observed in the nodules of bold seeded cultivars ensures hexose supply for meeting the energy and reducing power demands of nodules during the stage of active nitrogen fixation and probably may regulate carbon metabolism and nitrogen fixation. The higher activity of PEPC, MDH and IDH ensure the utilization of glycolytic product for bacteroid respiration. GS and GOGAT function as the main route for the assimilation of fixed nitrogen while GDH may function at higher $\mathrm{NH}_{4}^{+}$concentration in young and senescing lentil nodules.

\section{Acknowledgements}

Authors are grateful to Department of Biochemistry and Department of Plant breeding and Genetics to carry out this research work at Punjab Agricultural University, Ludhiana, during the PostGraduation programme.

\section{References}

Aleman, L., Ortega, J. L., Martinez-Grimes, M., Seger, M., Holguin, F. O., Uribe, D. J., Garcia-Ibilcieta, D. and SenguptaGopalan, C. 2010. Nodule-enhanced expression of a sucrose phosphate synthase gene member (MsSPSA) has a role in carbon and nitrogen metabolism in the nodules of alfalfa (Medicago sativa L.). Planta, 231:233-44

Bhatty, R. S. and Christison, G. I. 1984. Composition and nutritional quality of pea (Pisum sativum L.), fababean (Vicia faba L. spp. minor) and lentil (Lens culinaris Medik) meals, protein concentrates and isolates. Plant Foods Hum. Nutr., 34: 41.

Chopra, J., Kaur, N. and Gupta, A. K 2002. A comparative developmental pattern of carbon metabolism and pentose phosphate pathway in mungbean and lentil nodules. Acta Physiol. Plant. 24:67-72

Chopra, J., Kaur, N. and Gupta, A. K 2003. Changes in the activities of carbon metabolizing enzymes with pod development in lentil (Lens culinaris L.) Acta Physiol. Plant. 25:185-91

Chopra, J., Kaur, N. and Gupta, A. K. 1998. Carbohydrate status and sucrose metabolism in mungbean roots and nodules. Phytochem. 49:1891-95

Christeller, J. T., Laing, W. A. and Sutton, W. D. 1977. Carbon dioxide fixation by lupin root nodules. I. Characterization, association with phosphoenolpyruvate carboxylase, and correlation with nitrogen fixation during nodule development. Plant Physiol. 60: 47-50

Dey, P. M. 1986. Change in the forms of invertases during germination of 
mungbean seeds. Phytochem 25: 51-53.

Dixit, G. P., Katiyar, P. K. and Singh, B. B. 2011. Characterization of lentil (Lens culinaris Medik.) varieties based on morphological traits. J. Food Legumes 24:194-97.

Duke, S. H. and Ham, G. E. 1976. The effect of nitrogen addition on $\mathrm{N}_{2}$-fixation and on glutamate dehydrogenase and glutamate synthase activities in nodules and roots of soybeans inoculated with various strains of Rhizobium japonicum. Plant Cell Physiol. 17:1037-44.

Elliott, W. H. 1953. Isolation of glutamine synthetase and glutamotransferase from green peas. J. Biol. Chem. 201:661-72

Eriksson, O. 1999. Seed size variation and its effect on germination and seedling performance in the clonal herb Convallaria majalis. Acta Oecol. 20: 61-66.

Galvez, L., Gonzalez, E. M. and Arrese-Igor, C. 2005. Evidence for carbon flux shortage and strong carbon/nitrogen interactions in pea nodules at early stages of water stress. J. Exp. Bot. 56:2551-56.

Gordon, A. J., Minchin, F. R., James, C. L. and Komina, O. 1999. Sucrose synthase in legume nodules is essential for nitrogen fixation. Plant Physiol. 120:867-77

Gupta, D. S., Thavarajah, D., Knutson, P., Thavarajah, P., McGee, R. J., Coyne, C. J. and Kumar, S. 2013. Lentils (Lens culinaris L.), a rich source of folates. J. Agri. Food Chem. 61(32): 7794-7799.

Hodges, M. 2002. Enzyme redundancy and the importance of 2-oxoglutarate in plant ammonium assimilation. J. Exp. Bot. 53:905-16.

Hojjat, S. S. 2011. Effect of seed size on germination and seedling growth of some lentil genotypes. Int J Agri. crop sci. 3 (1):1-5.

IPGA (2015). Pulse India: Vol: 1 Issue 04
Kerr, T. S., Torres, W. K. and Huber, S. C. 1987. Resolution of two molecular forms of sucrose phosphate synthase from maize, soybean and spinach leaves. Planta, 170:515-19.

Lloret, F., Casanovas, C. and Penuelas, J. 1999. Seedling survival of Mediterranean shrub land species in relation to root: shoot ratio, seed size and water and nitrogen use. Funct. Ecol. 13:210-216.

Lodwig, E. and Poole, P. 2003. Metabolism of rhizobium bacteroids. Crit. Rev. Plant Sci. 22:37-78.

Lowry, O. H., Rosebrough, N. J., Farr, A. L. and Randall, R. J. (1951. Protein measurement with folin phenol reagent. J. Biol. Chem. 193:265-75

Mariana, M. L., Lechner, L., Zabaleta, E. J. and Salerno, G. L. 2013. A mitochondrial alkaline/neutral invertase isoform (A/N-InvC) functions in developmental energy-demanding processes in Arabidopsis. Planta 237:813-22.

Masclaux-Daubresse, C., Reisdorf-Cren, M., Pageau, K., Lelandais, M., Grandjean, O. and Kronenberger, J. 2006. Glutamine synthetase-glutamate synthase pathway and glutamate dehydrogenase play distinct roles in the sink-source nitrogen cycle in tobacco. Plant Physiol. 140:444-56.

Miflin, B. J. and Lea, P. J. 1980. Ammonium assimilation. In: The Biochemistry of plants. Amino acids and derivatives 169-202.

Misra, S. and Oaks, A. 1981. Enzymes of nitrogen assimilation during seed development in normal and high lysine mutants in maize (Zea mays, W64A). Can. J. Bot. 59:2375-43.

Moles, A. T. and Westoby, M. 2004. What do seedlings die from and what are the implications for evolution of seed size. Oikos. 106:193-199. 
Nelson, N. 1944. A photometric adaptation of the somogyil method for determination of glucose. J. Biol. Chem. 153:375-80.

Normura, M., Mai, H. T., Fujii, M., Hata, S., Izui, K. and Tajima, S. 2006. Phosphoenolpyruvate carboxylase plays a crucial role in limiting nitrogen fixation in Lotus japonicus nodules. Plant Cell Physiol. 47: 613-21.

Rao, S. K. 1981. Influence of seed size on field germination, seedling vigour, yield and quality of self-pollinated crops: a review. Agri. Rev. 2: 95-101.

Rathore, P. S. 2002. Techniques and management of field crop production. India Agrobios.

Schulze, J., Shi, L. F., Blumenthal, J., Samac, D. A., Gantt, J. S. and Vance, C. P. 1998. Inhibition of alfalfa root nodule phosphoenolpyruvate carboxylase through an antisense strategy impacts nitrogen fixation and plant growth. Phytochem.49: 341-46.

Shahin, M. A., Symon, S. J. and Ning, W. 2012. Predicting dehulling efficiency of lentil based on seed size and shape characteristics measured with image analysis. Qual. Assur. Saf.crop. 4: 9-16.

Singh, S., Singh, I., Gill, R. K., Kumar, S. and Sarkar, A. 2009. Genetic studies for component characters in large seeded exotic lines of lentil. J. Food legumes. 22:229-32.
Sinha, J. P., Vishwakarma, M. K. and Sinha, S. X. 2009. Quality improvement in lentil (Lens culinaris Medic) seed through mechanical seed processing. $J$. Res. SKUAST-J 8: 7-17.

Stitt, M., Lunn, J. and Usadel, B. 2010. Arabidopsis and primary photosynthetic metabolism - more than the icing on the cake. Plant J, 61: 1067-1091.

Sun, J., Zhang, J., Larue, C. T. and Huber, S. C. 2011. Decrease in leaf sucrose synthesis leads to increased leaf starch turnover and decreased RuBP regeneration-limited photosynthesis but not Rubisco limited photosynthesis in Arabidopsis null mutants of SPSA1. Plant Cell Environ. 34:592-604.

Tobin, A. K. and Yamaya, T. 2001. Cellular compartmentation of ammonium assimilation in rice and barley. $J$ Exp Bot 52: 591-604.

Tyagi, S. D. and Khan, M. H. 2010. Studies on genetic variability and interrelationship among the different traits in Microsperma lentil (Lens culinaris Medik). J. Agric. Biotech. 2:15-20.

Vance, C. P. and Stade, S. 1984. Alfalfa root nodule carbon dioxide fixation. II. Partial purification and characterization of root nodule phosphoenolpyruvate carboxylase. Plant Physiol.75:261-64.

\section{How to cite this article:}

Vivek Chandra Verma, Satvir Kaur, Anil Kumar Gupta, Jagmeet Kaur, Sarvjeet Singh and Surabhi. 2017. Changes in the Activity of Carbon and Nitrogen Metabolising Enzymes in Nodules of Bold and Small Seeded Lentil Cultivars. Int.J.Curr.Microbiol.App.Sci. 6(12): 33113320. doi: https://doi.org/10.20546/ijcmas.2017.612.385 